\title{
اتجاهات أساتذة التعليم الثانوي نحو الإشراف التريوي
}

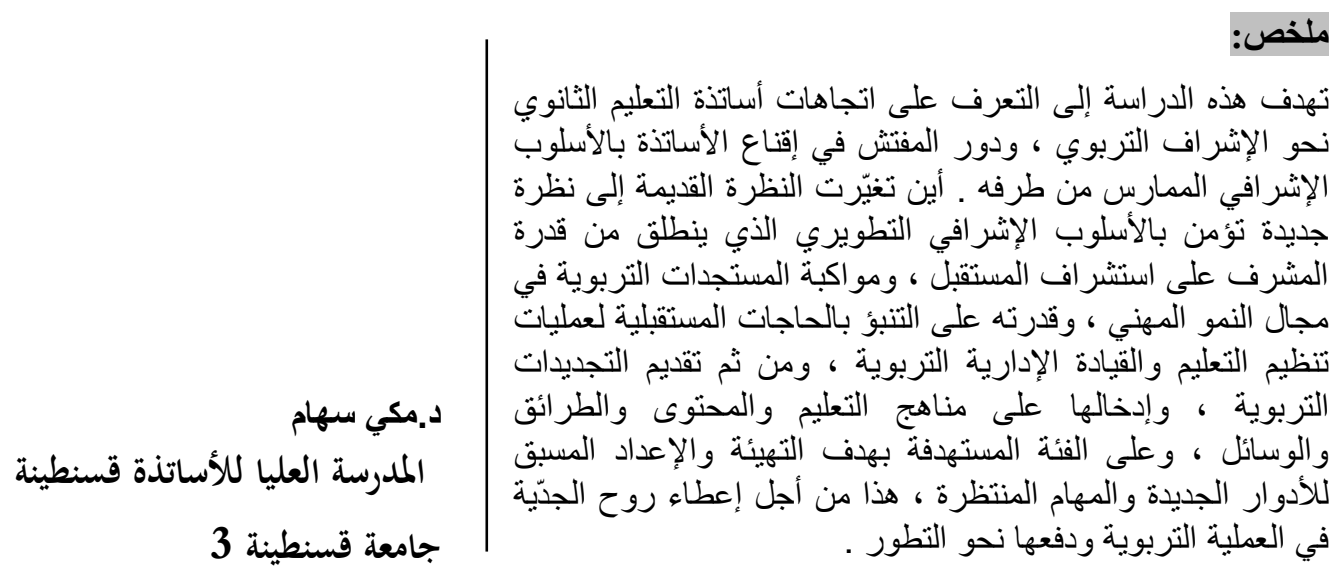

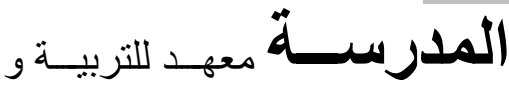

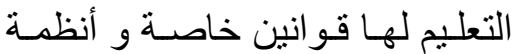

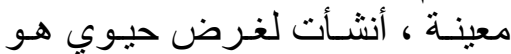

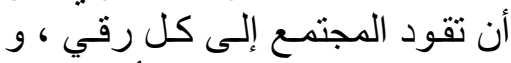

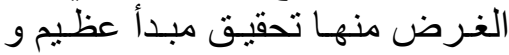
فكرة سامية ، تلكلك الفكرة هي تربية

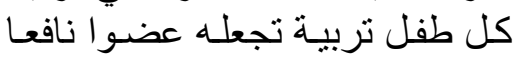

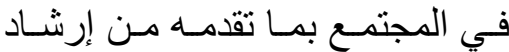

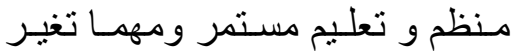

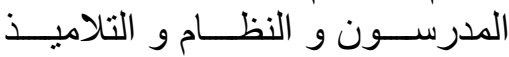

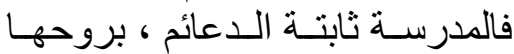

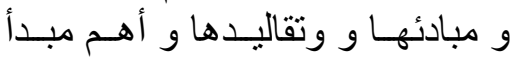

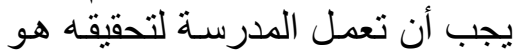

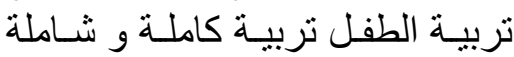

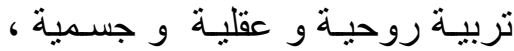
9 وطنيـة ووجدانيـة و خلقيـة ونية اجتماعية ، حتى تؤدي وظيفتها

\section{Abstract :}

This study aims at identifying the attitudes of secondary school teachers towards educational supervision and the role of the inspector in persuading teachers by his/her applied supervisory style while the old view has changed to a new one that believes in the developmental supervisory style. This latter starts from the ability of the supervisor to explore the future and to cope with new developments in education within the field of professional development. In addition to , his/her ability to anticipate the needs of organising learning and administrative educational command 's processes. Then, to provide educational innovations and insert them in the educational procedures, content, methods, as well as, the target group in order to prepare for the new roles and tasks ahead. This procedure aims at giving the spirit of seriousness in education process and pushing it towards development . 
و وتقوم بواجبها خير قيام، وليست وظيفة المدرسة تعليم النشء القراءة والكتابة

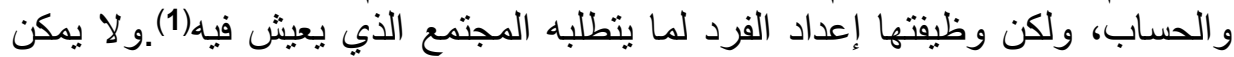

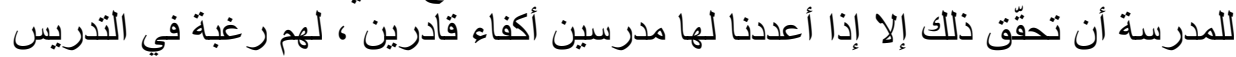

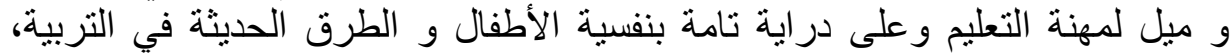

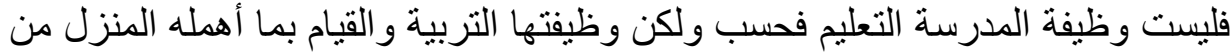

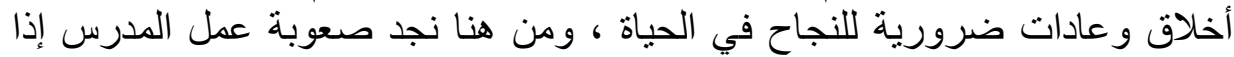

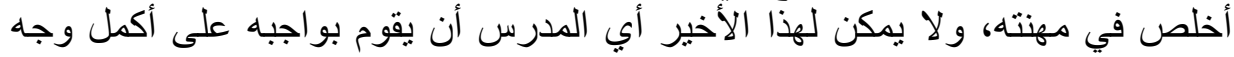

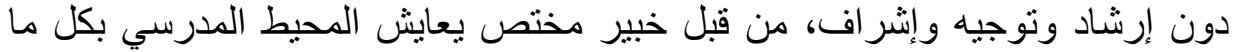

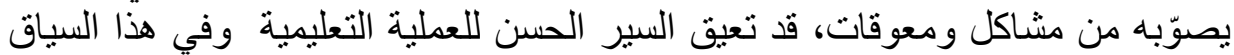

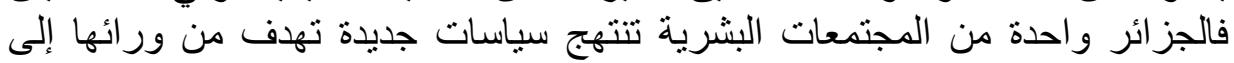

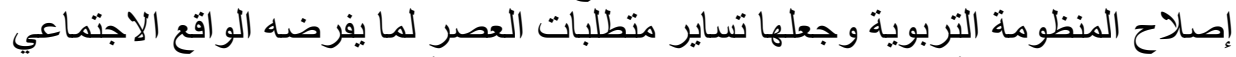

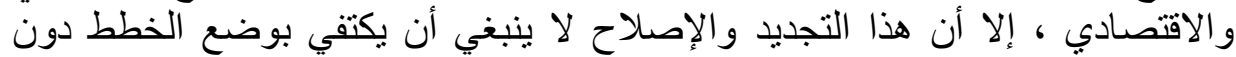

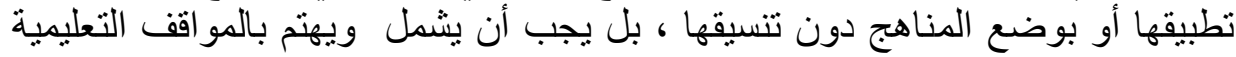

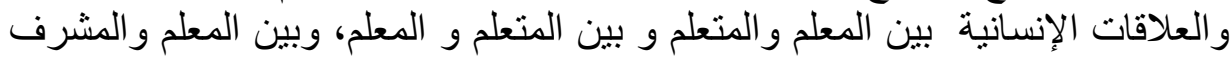
باعتباره قائد تربوي من جهة ومطبق للأساليب الإشر افية الموضوعة العة من جهة أخرى ـ

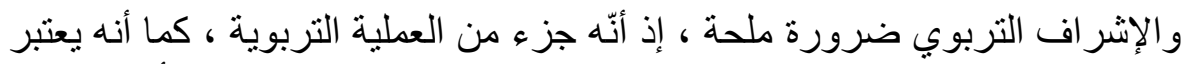

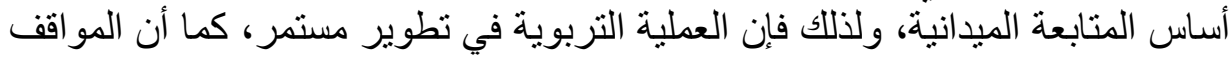

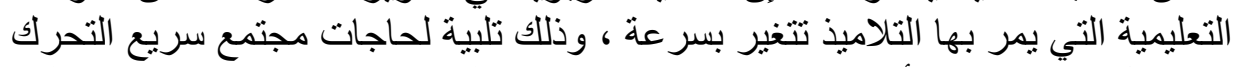

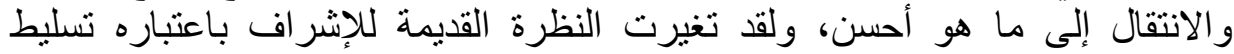

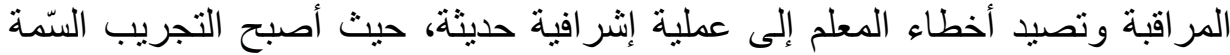

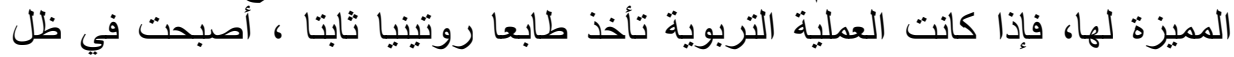

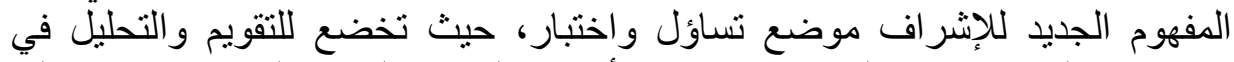

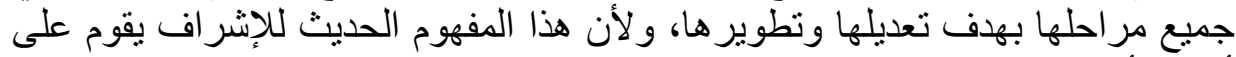

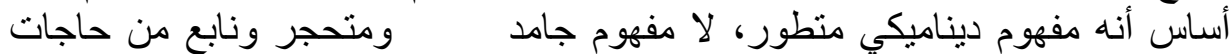

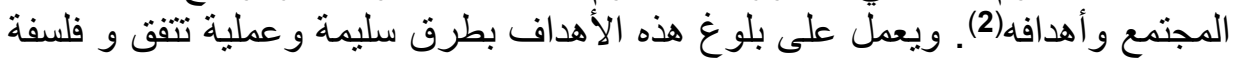

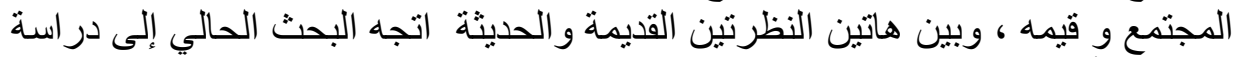
اتجاهات أساتذة التعليم الثانوي نحو العلمية الإشر افية، و المشرف التربية الفئهي الذي تلتوقف 
بمستوى أدائه نجاح العملية الإشرافية على المستوى الإجرائي الذي تتبلور فيه كل الجهود سواء من الناحية العملية أو الإدارية والأية علية العنطة التربوية المختلفة.

مشكلة الدراسة: تحمل المهمة الإشرافية صيغا موضوعية كالمر اقبة الميدانية

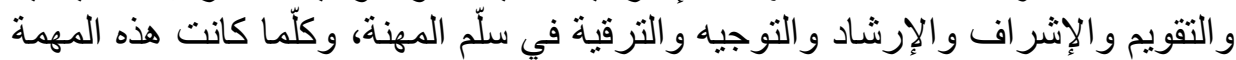

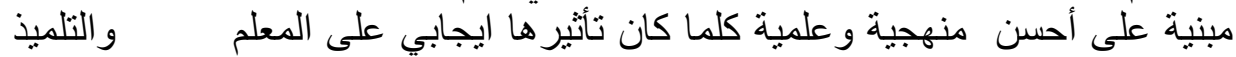
وبالتالي على العملية التربوية ككل. مله علية

ولماّ كانت الجزائر في طريقها إلى أن تعد نظاما تعليميا متكاملا يلائم ظروف

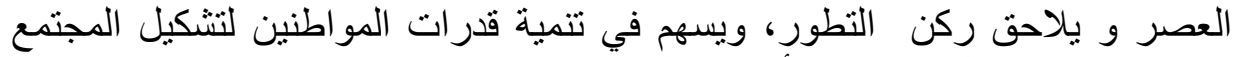

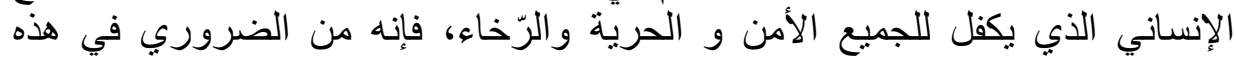

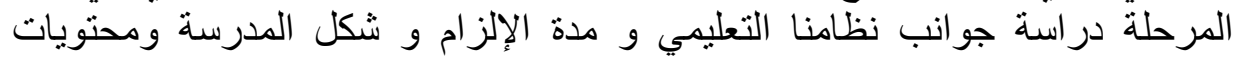

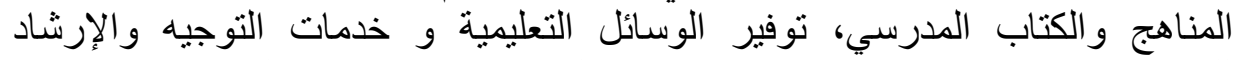

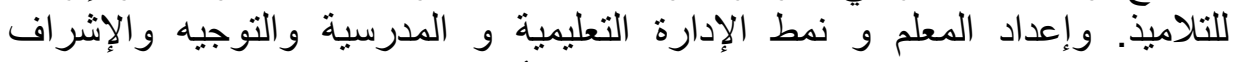
التربوي، حتى تسهم التربية بدور فعال في تحقيق أهداف المجتمع.

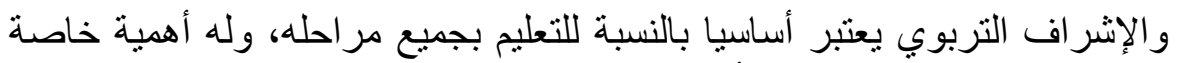

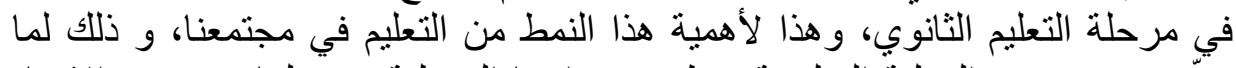

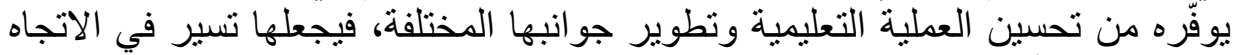

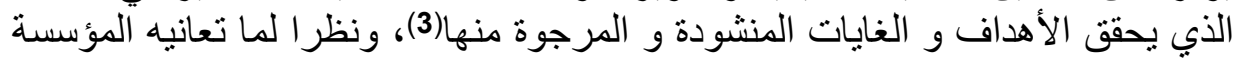

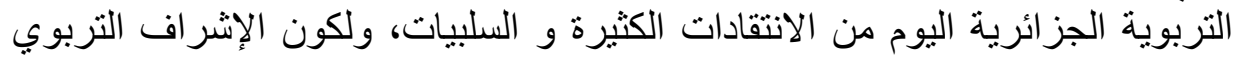

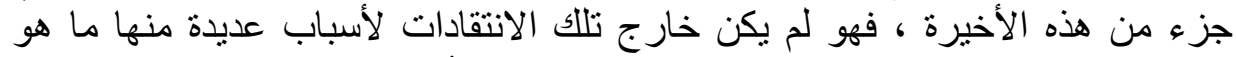

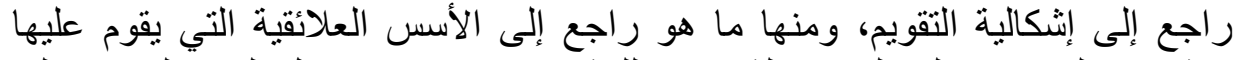

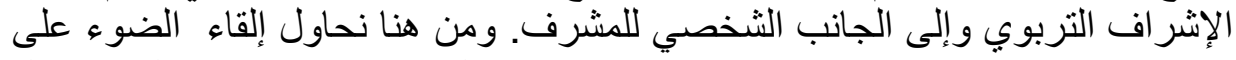

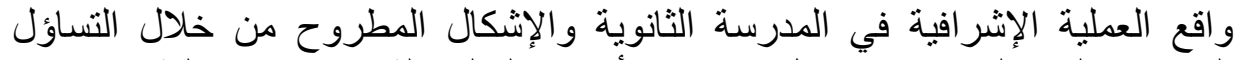
المحوري لهذا البحث هو: هل اتجاهات أساتذة التعليم الثانوي نحو عملية الإنشراف التفال

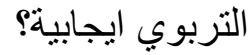

فروض و مؤشرات الاراسة : انطلاقا من الجانب النظري للار اسة والأسئلة التي

وردت في الإطار العام لمشكلة البحث تم بتاء الفرضئ الفيات الآتية : 
الفرضية العامة: اتجاهات أساتذة التعليم الثانوي نحو عملية الإشراف التربوي

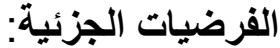

1- اتجاهات أساتذة التعليم الثانوي نحو الصفات الثخصية للمشرف التربوي

2- اتجاهات أساتذة التعليم الثانوي نحو الجانب العلائقي للمشرف ايجابية.

3- اتجاهات أساتذة التعليم الثانوي نحو الجانب التقويمي للمشرف التربوي ايجابية

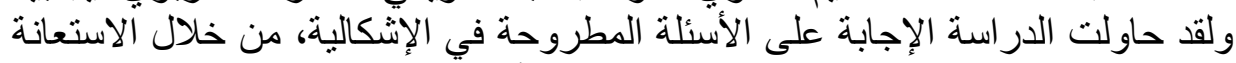

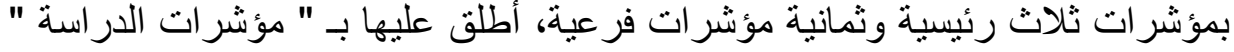

عينة الدراسة : إن اختيار العينة التي سيجري عليها الباحث بحثه من أهم الأعمال

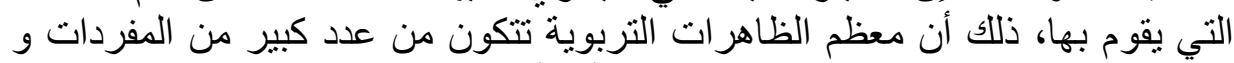

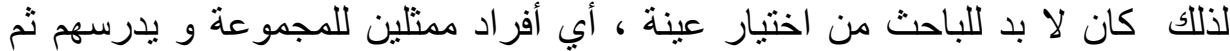

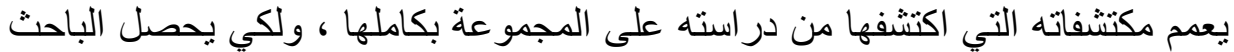

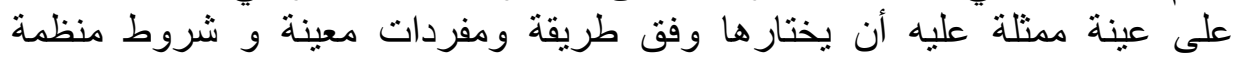

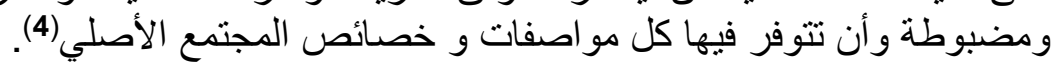

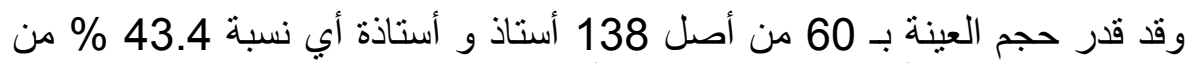
مجتمع الدراسة ، و قد أخذنا عينة البحث من أربعة ثانويات موجودة بيلدية قسنطينة و و

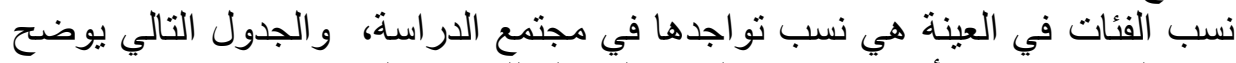

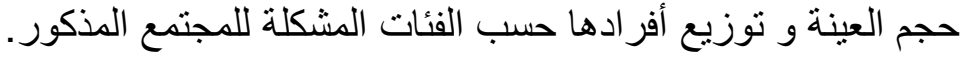

\section{جدول رقم (1) :يمثل توزيع العينة حسب الفئات المشكلة .}

\begin{tabular}{|c|c|c|c|}
\hline حجم فئات & حجم & النسبة & مجموع \\
\hline
\end{tabular}


مكي سهام

\begin{tabular}{|c|c|c|c|c|}
\hline العينة & العينة & المئوية & الفئات & \\
\hline 16 & \multirow{4}{*}{60} & 26.66 & 33 & ثانوية الأختين \\
\hline 20 & & 33.33 & 45 & ثانوية يو غرطة \\
\hline 10 & & 16.66 & 32 & ثانوية الطيب \\
\hline 14 & & 23.33 & 28 & ثانوية سمية \\
\hline 60 & 43.4 & 100 & 138 & المجموع \\
\hline
\end{tabular}

ـ المجال البشري: اقتصر البحث على معلمي ومعلمات المدرسة الثانوية.

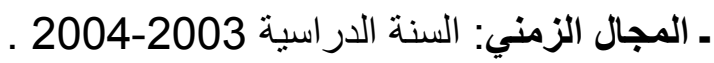

ـ المجال المكاني: لإجراء الدراسية الميدانية تم اختيار مدينة قسنطينة نظرا

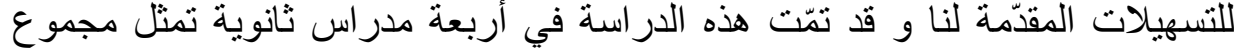

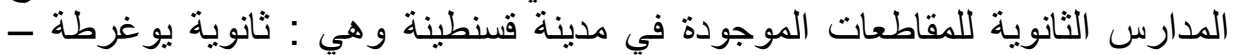
ثانوية الطيب العقبي ـ ثانوية سمية ـ ثنانوية الأختين سعدان.

منهج الدراسة : إن نوع الدراسة وأهدافها هي عوامل لها دور هام في تحديد المنهج

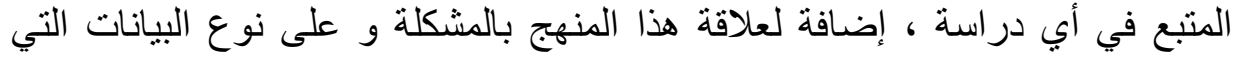

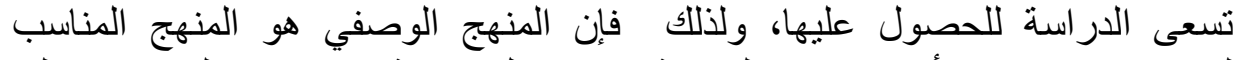

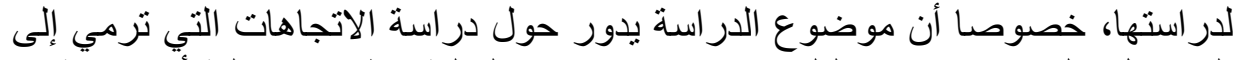

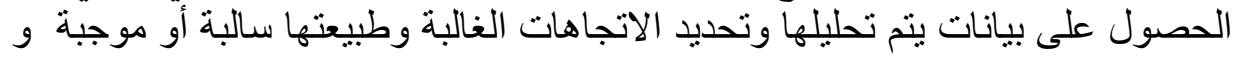

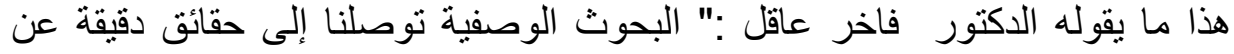

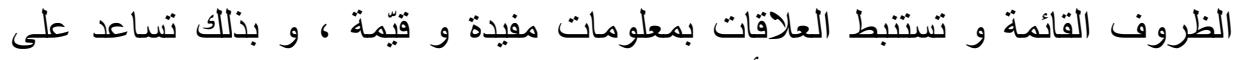

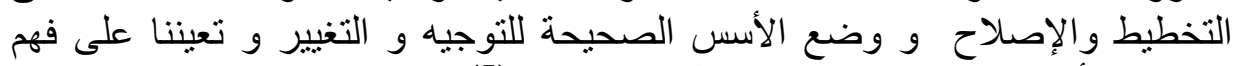

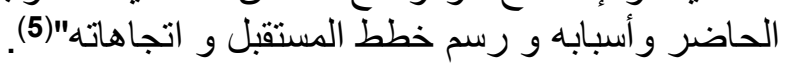


أدوات جمع البيانات: لجمع البيانات الخاصة لهذه الدراسة صمّمت أداة الاستبيان

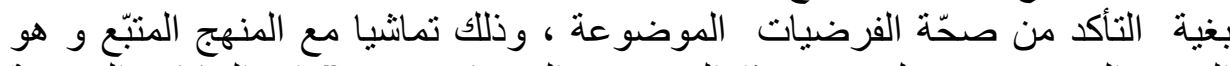

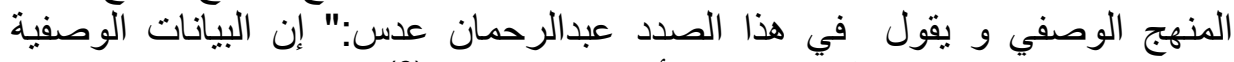

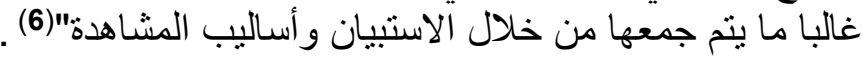

الاستبيان : أو الاستخبار أداة مفيدة من أدوات البحث العلمي، وهي مستعملة على التى

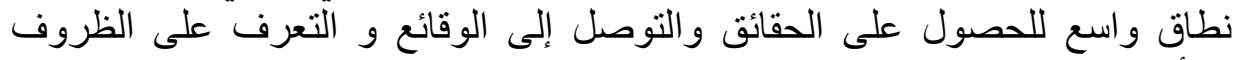

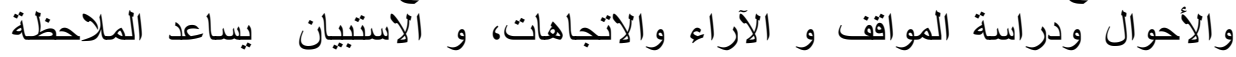

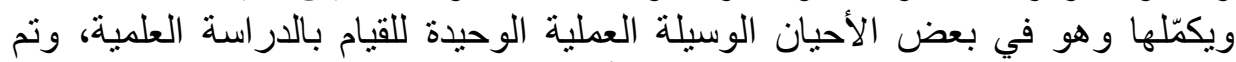

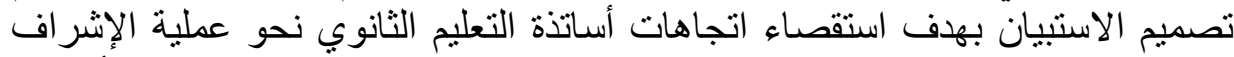

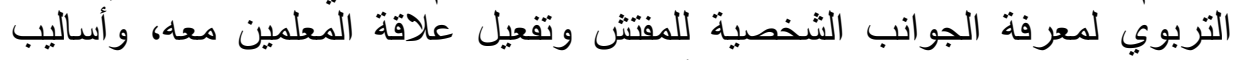

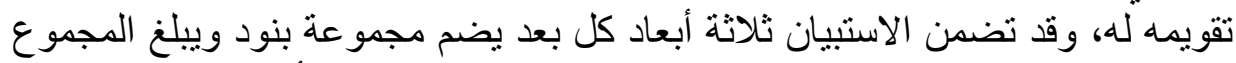

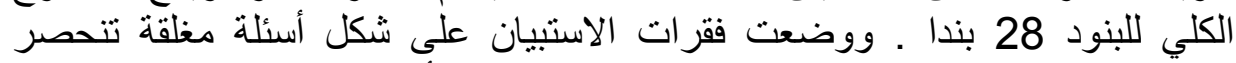
الإجابة عليها في ثلاث احتمالات:مو افق، غير موافق، لا أدري.

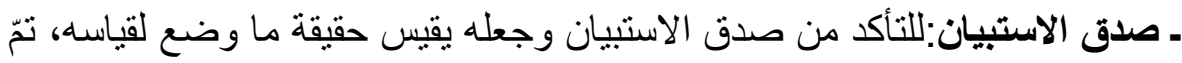

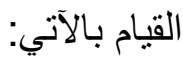

ـ صدق المحكّمين: تمّ عرض الاستبيان في صورته الأولية على مجموعة من

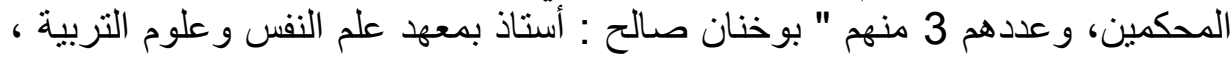

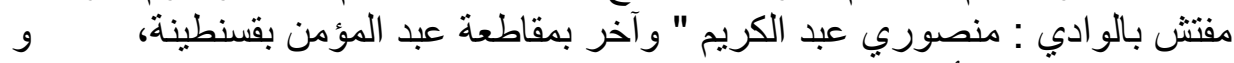

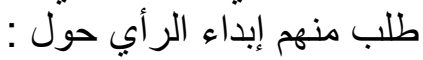

- صياغة أسئلة الاستبيان من جانبين : الوضوح ائ وسلامة : اللغة .

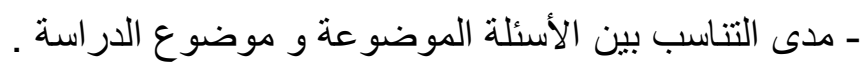

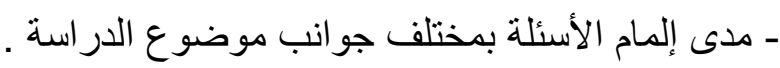

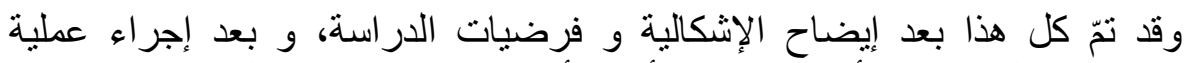

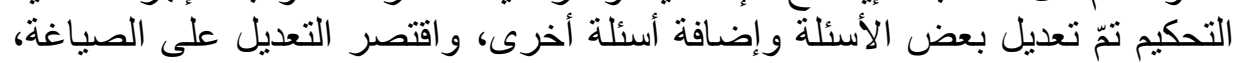

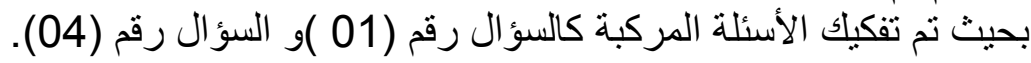


ومن خلال نتائج التحكيم لمحنا صدق الاستبيان بدرجة عالية من خلال ملاحظات

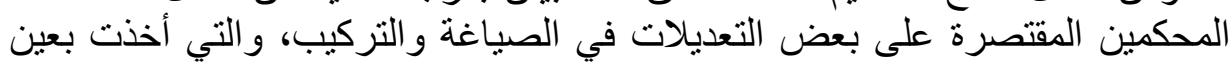

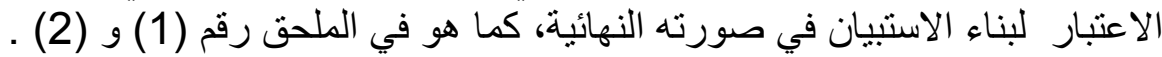
كيفية عرض وتحليل البيانات: في بحثنا هذا لم نكتف بعرض البيانات الكيفية

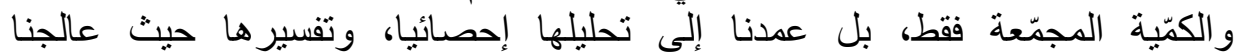

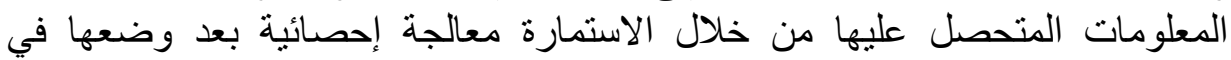

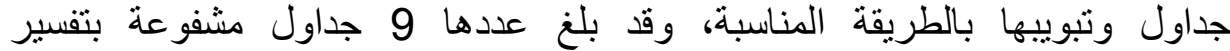
وتحليل للأرقام التي احتوتها بما يتناسب و أبعاد الدراسة .

أما فيما يخص الأساليب الإحصائية المستخدمة في مجال عرض البيانات الكمّية ،

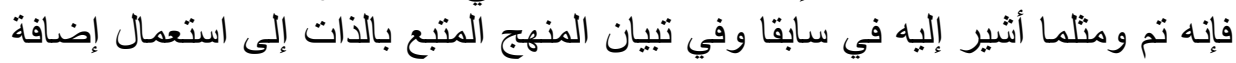
للنسب المئوية وفق المعادلة: النسبة المئوية : عدد التكرارات $x$ x 100 / مجموع التكرارات قد تم قياس شدة الاتجاه حيث تمثل (-) الاتجاه السالب، و (+) الاتجاه الموجب ، وتبع بتحليل وتفسير معقى .

عرض وتحليل البيانات والتعليق عليها : أ- النتائج العامة للمؤشر الأول : الصفات الثيل الثخصية أ-1- جدول رقم (2) : يمثل الصر امة والتظظيم في العمل :

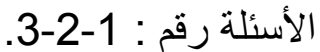

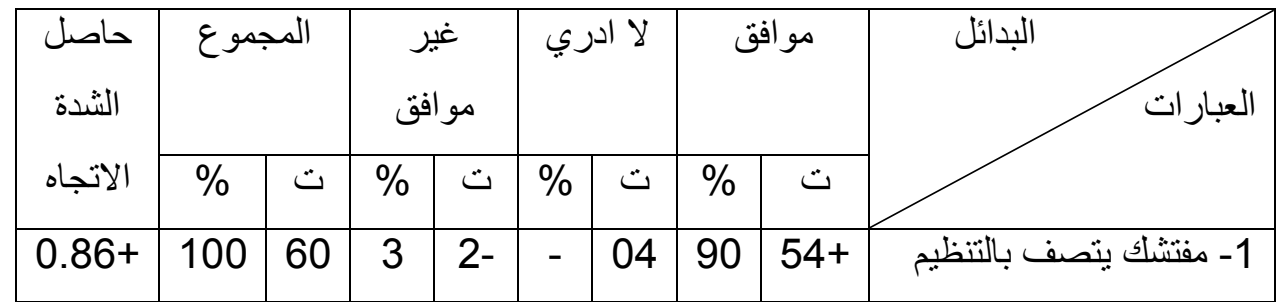




\begin{tabular}{|c|c|c|c|c|c|c|c|c|c|}
\hline $0.38+$ & 100 & 60 & 18 & $\begin{array}{l}- \\
11\end{array}$ & - & 15 & 57 & $54+$ & 2- مفتشك صسارم \\
\hline $0.81+$ & 100 & 60 & 7 & 4- & - & 03 & 88 & $53+$ & 3- مفتشك حريص على \\
\hline
\end{tabular}

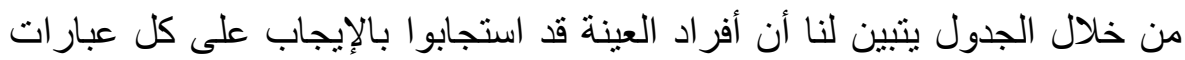

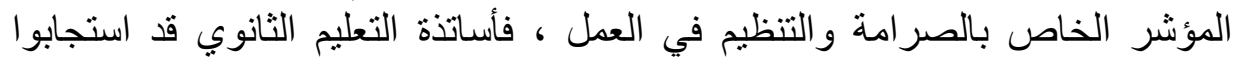

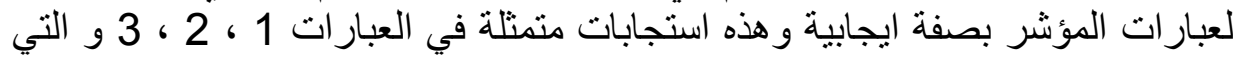

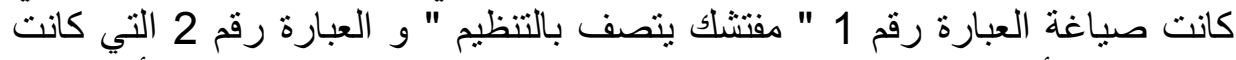

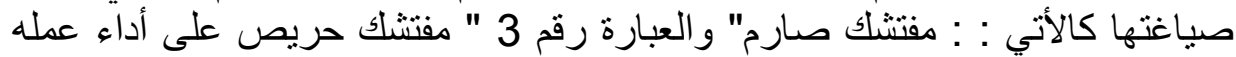

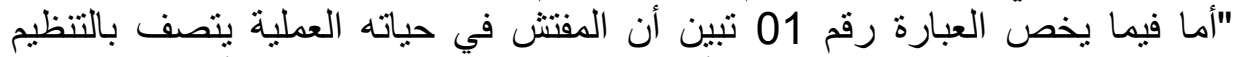

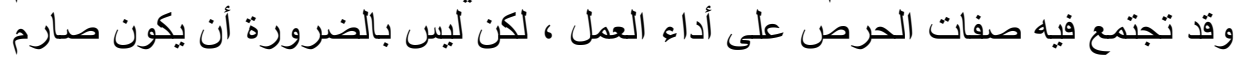

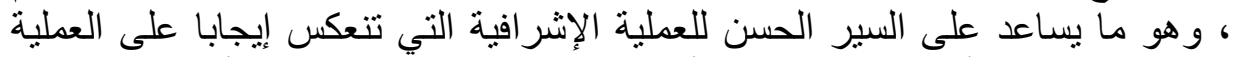

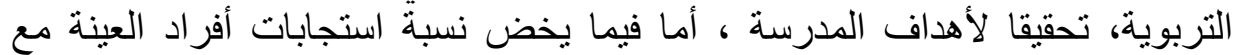
عبارات المؤشر فكانت بنسبة 90 \% أي 54 مبحوث، و وعلى العموم شدة الاتجاه هي التي

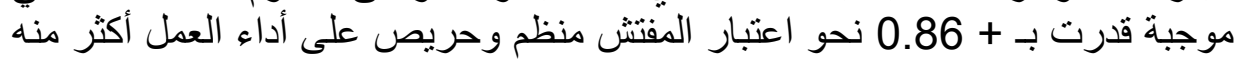
صارم ، و هذا ما تؤكده النتائج السابقة.

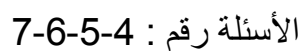

-2- جدول رقم (2) : يمثل الصرامة و التنظيم في العمل :

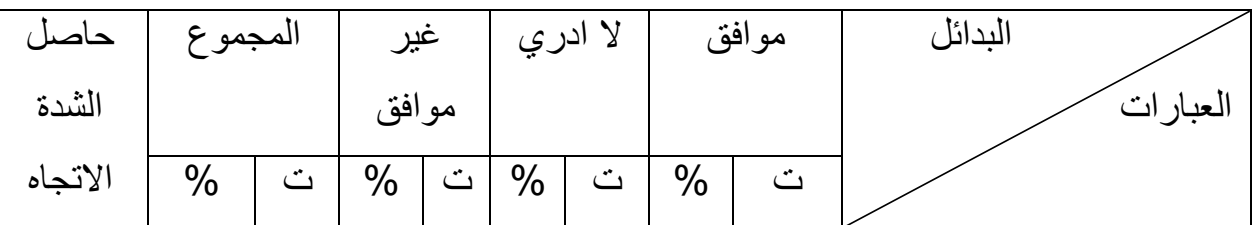




\begin{tabular}{|c|c|c|c|c|c|c|c|c|c|}
\hline $0.75+$ & 100 & 60 & 5 & - & - & 09 & 80 & $48+$ & 4- مفتشك يهتم بعملك \\
\hline $0.7+$ & 100 & 60 & 10 & 6 & - & 06 & 80 & $48+$ & 5-يتميز مفتشك بالجدارة في \\
\hline $0.53+$ & 100 & 60 & 12 & 7 & - & 14 & 65 & $39+$ & 6- له القدرة في بث الثقة في \\
\hline $0.4+$ & 100 & 60 & 15 & 9 & - & 18 & 65 & $33+$ & 7- يقدم للك المساعدة \\
\hline
\end{tabular}

فيما يخص نسبة استجابات أفر اد العينة مع عبار ات المؤشر فكانت نسبة 80 \% أي العبا

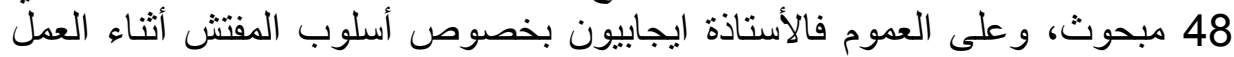

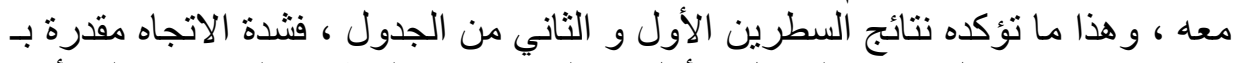

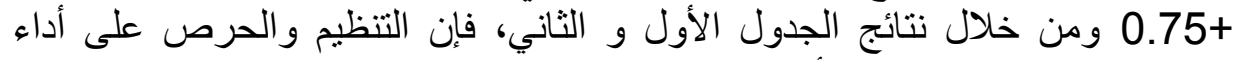

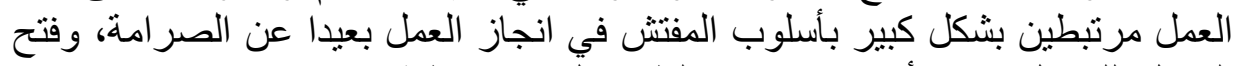

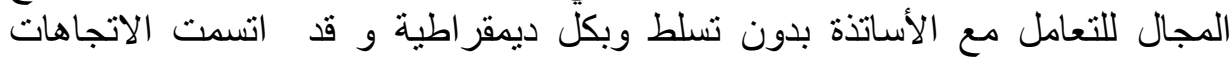

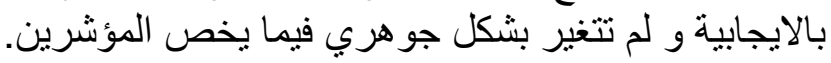

-3- جدول رقم (3) : يمثل تعامل المفتش مع الأستاذة :

الأسئلة رقم : 8-10-11-11

\begin{tabular}{|c|c|c|c|c|c|c|c|c|c|}
\hline حاصل الثدة & \multicolumn{2}{|c|}{ المجموع } & \multicolumn{2}{|c|}{ غو افق } & \multicolumn{2}{|c|}{ لا ادري } & \multicolumn{2}{|c|}{ مو افق } & \multirow[t]{2}{*}{ البدائل } \\
\hline الاتجاه & $\%$ & ت & $\%$ & ت & $\%$ & ت & $\%$ & ت & \\
\hline
\end{tabular}




\begin{tabular}{|c|c|c|c|c|c|c|c|c|c|}
\hline $0.53+$ & 100 & 60 & 12 & 7- & - & 14 & 65 & $39+$ & 8- يتقبل المفتش أراك \\
\hline $0.61+$ & 100 & 60 & 10 & 6- & - & 11 & 72 & $43+$ & 9- ملاحظات المفتش \\
\hline 0.06- & 100 & 60 & 32 & $\begin{array}{l}- \\
19\end{array}$ & - & 26 & 25 & $15+$ & 10- تسامحه معك عند في الخطأ \\
\hline $0.08+$ & 100 & 60 & 33 & $\begin{array}{l}- \\
20\end{array}$ & - & 15 & 42 & $25+$ & 11- مفتى ابتكار أفكار جديدة له القدرة \\
\hline
\end{tabular}

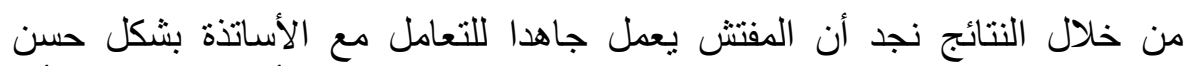

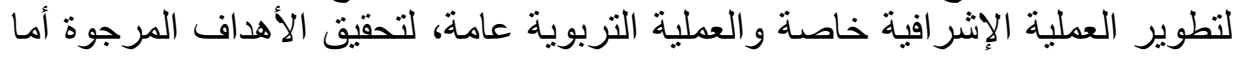

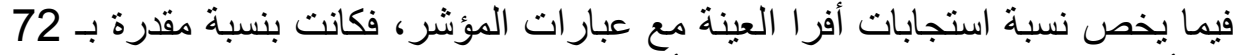

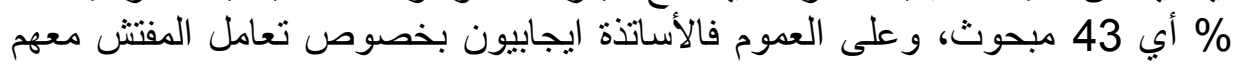

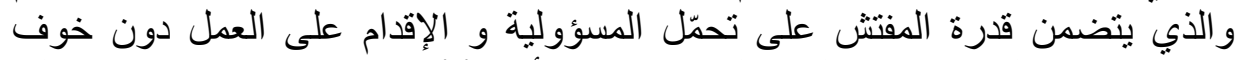

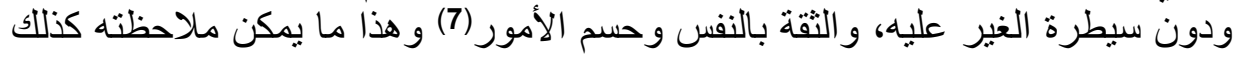
من خلال النموذجين السابقين، وهذا ما تؤكدّه شدة الاتجاه المقدرة بـ +0.61.

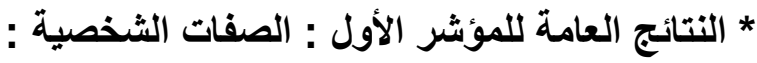

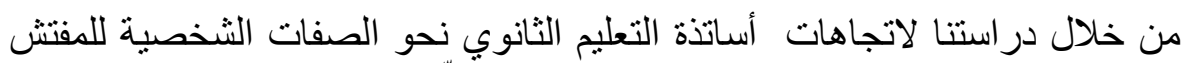

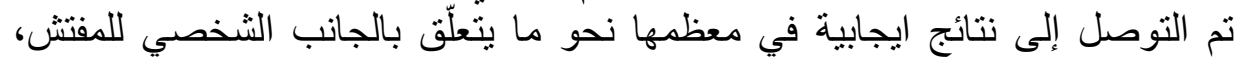

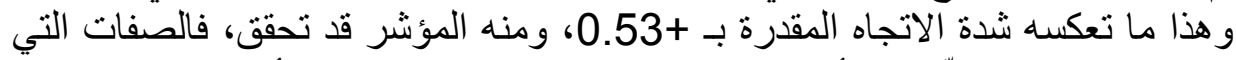

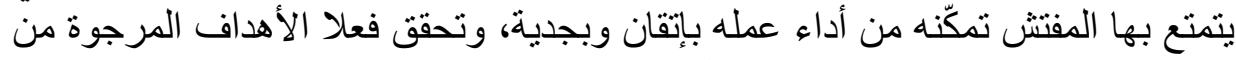

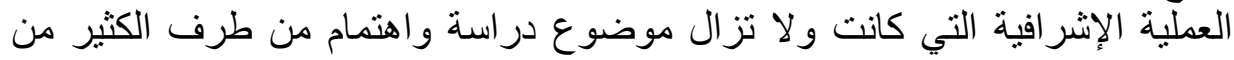

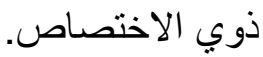
ب- النتائج العامة للمؤشر الثاني : الجاتب العلائقي: 
ب-1- جدول رقم (05) :يمثل طبيعة العلاقة الموجودة بين المفتش و الأستاذ:

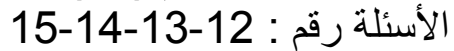

\begin{tabular}{|c|c|c|c|c|c|c|c|c|c|}
\hline \multirow{2}{*}{ الثاتدل } & \multicolumn{2}{|c|}{ المجموع } & \multicolumn{2}{|c|}{ مو غير } & \multicolumn{2}{|c|}{ لا ادري } & \multicolumn{2}{|c|}{ مو افق } & \multirow[t]{2}{*}{ البدائل } \\
\hline & $\%$ & ت & $\%$ & $ت$ & $\%$ & ت & $\%$ & ت & \\
\hline $0.08+$ & 100 & 60 & 33 & $\overline{20}$ & - & 15 & 42 & $25+$ & التعليمات على على الأساتذة المفتش \\
\hline $0.65+$ & 100 & 60 & 10 & 6- & - & 9 & 75 & $45+$ & بسط روح التعاون المفتش على \\
\hline $0.11+$ & 100 & 60 & 32 & $\overline{19}$ & - & 15 & 43 & $26+$ & 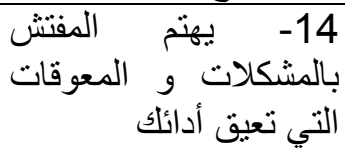 \\
\hline $0.58+$ & 100 & 60 & 8 & 5- & - & 15 & 67 & $40+$ & الرجأي. \\
\hline
\end{tabular}

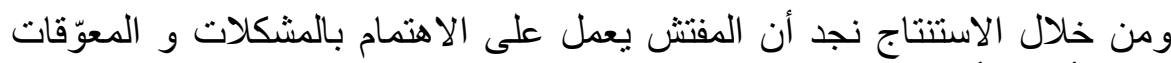

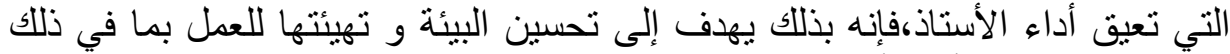
العلاقات الموجودة أثناء أداء العملية الإثر افية.

أما فيما يخص نسبة الاستجابات مع عبار ات المؤشر فكانت بنسبة مقدرة بـ 75 \%

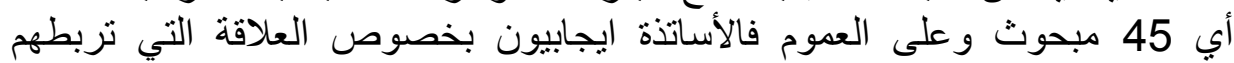

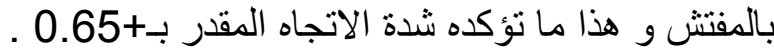
ب-2- جدول رقم (06) : يمثل احتر ام و رضا الأستاذ للمفتش: الأسئلة رقم : 19-16-17-19

\begin{tabular}{|c|c|c|c|c|c|c|c|c|c|}
\hline حاصل & \multicolumn{2}{|c|}{ المجموع } & \multicolumn{2}{|c|}{ مو افقير } & \multicolumn{2}{|c|}{ لا ادري } & \multicolumn{2}{|c|}{ 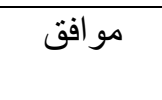 } & البدائل \\
\hline الاتجاه & $\%$ & ت & $\%$ & ت & $\%$ & ت & $\%$ & ت & \\
\hline 0.09 & 100 & 60 & 33 & - & - & 15 & 42 & $25+$ & 16 يجتمع المفتش دع \\
\hline
\end{tabular}




\begin{tabular}{|c|c|c|c|c|c|c|c|c|c|}
\hline & & & & 20 & & & & & في الفصاتذة لمناقتشة القصور \\
\hline $0.36+$ & 100 & 60 & 15 & 9- & - & 20 & 52 & $31+$ & زيارة المفتش بلفصلك الرئاء \\
\hline $0.81+$ & 100 & 60 & 5 & 3- & - & 5 & 87 & $52+$ & معا أثناء قيامه بعمله العامل \\
\hline $0.6+$ & 100 & 60 & 15 & 9- & - & 10 & 75 & $45+$ & زميل لـ فتع المهنة معام كأنك \\
\hline
\end{tabular}

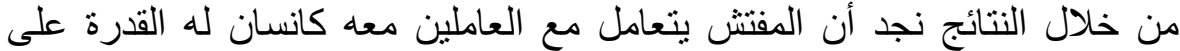

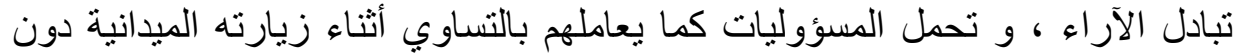

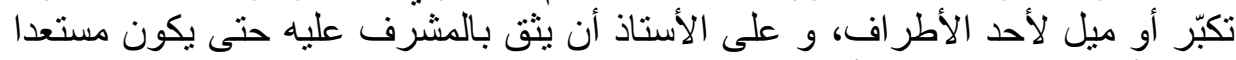

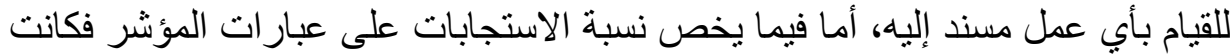
النسبة مقرة بـ87\% أي 52 مبحوثو على العموم فان شدة الاتجاه العام للأساتذة موجب التبّة

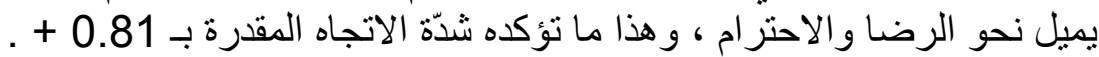

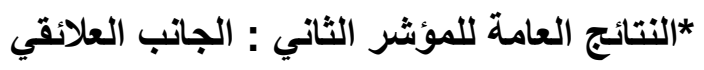

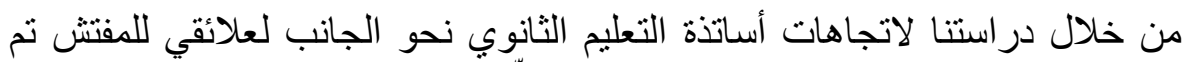

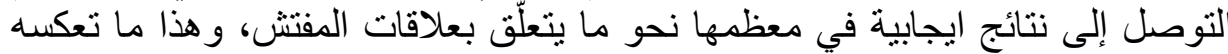
شدة الاتجاه المقدرة بـ + 0.40 ومنه المؤشر الثناني قد تحقق. بعان.

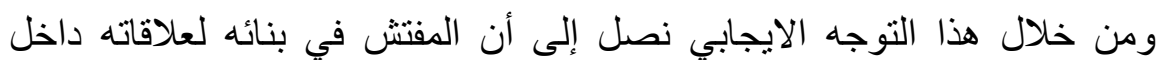

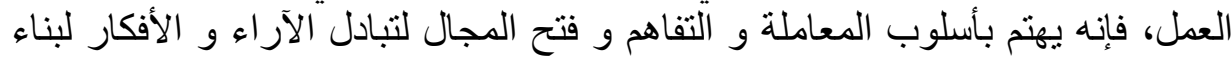
علاقات إنسانية تخدم حقيقة العملية التربوية.

جـ النتائج العامة للمؤشر الثالث : الجاتب التقييمي: ج-1- جدول رقم (07) : يمثل الوسائل المعتمدة في التقييم:

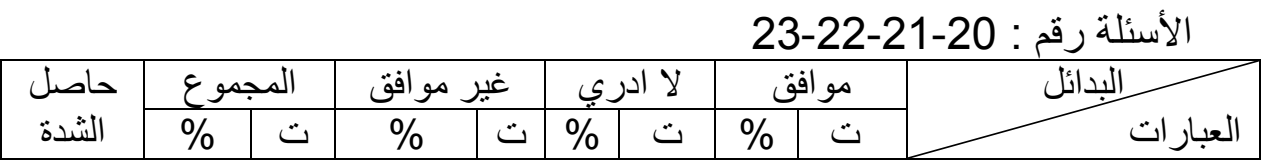




\section{مكي سهام}

\begin{tabular}{|c|c|c|c|c|c|c|c|c|c|}
\hline الاتجاه & & & & & & & & & \\
\hline $0.55+$ & 100 & 60 & 11.33 & $\overline{7}$ & - & .13 & 67 & $40+$ & 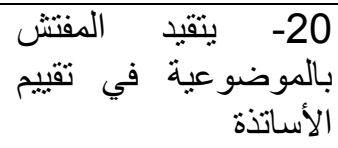 \\
\hline $0.88+$ & 100 & 60 & 3 & $\overline{2}$ & - & .3 & 92 & $55+$ & التلاميذّ بعين الاعتبار نشاط \\
\hline $0.71+$ & 100 & 60 & 5 & $\overline{3}$ & - & .11 & 77 & $46+$ & 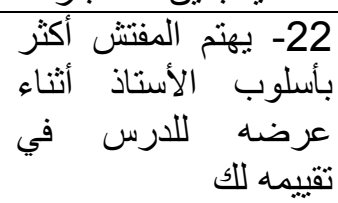 \\
\hline $0.28+$ & 100 & 60 & 13 & $\overline{8}$ & - & .9 & 72 & $43+$ & 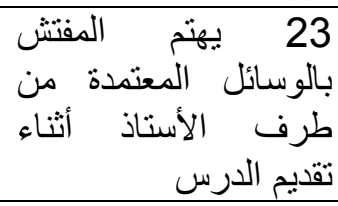 \\
\hline
\end{tabular}

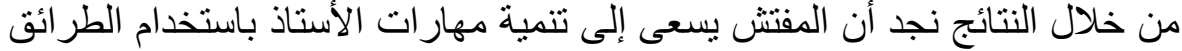

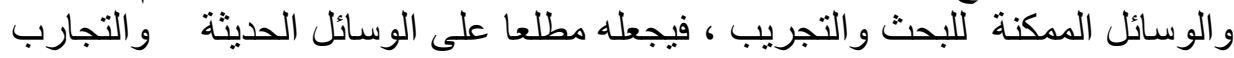

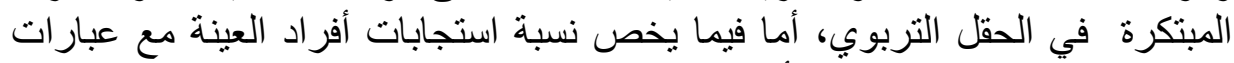

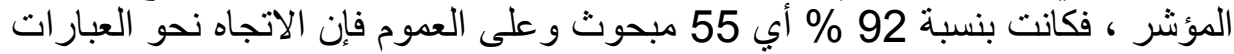

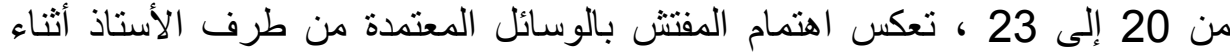

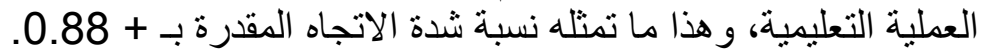

ج-2- جدول رقم (08) :يمثل أساليب التقييم:

الأسئلة رقم : 24-26-26-25

\begin{tabular}{|c|c|c|c|c|c|c|c|c|c|}
\hline \multirow{2}{*}{ حاصل الثندة } & \multicolumn{2}{|c|}{ المجموع } & \multicolumn{2}{|c|}{ غير مو افق } & \multicolumn{2}{|c|}{ لا ادري } & \multicolumn{2}{|c|}{ مو افق } & \multirow[t]{2}{*}{ البدائل } \\
\hline & $\%$ & $ت$ & $\%$ & $ت$ & $\%$ & $ت$ & $\%$ & $ت$ & \\
\hline $0.6-$ & 100 & 60 & 75 & 45- & - & 6 & 15 & $9+$ & تقيمه لمستوى لا ير التعليمي للأستاذ أثناء \\
\hline 00 & 100 & 60 & 37 & 22- & - & 16 & 37 & $22+$ & 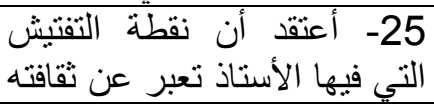 \\
\hline
\end{tabular}




\begin{tabular}{|c|c|c|c|c|c|c|c|c|c|}
\hline & & & & & & & & & المهنبة \\
\hline $0.15-$ & 100 & 60 & 49 & 29- & - & 8 & 38 & $33+$ & سنوات الخدمة أثناء التقييم الاعتبار \\
\hline $0.26+$ & 100 & 60 & 51 & 3- & - & 16 & 32 & $19+$ & 27 - لاناني لعطية الإشي المفتش الوقت \\
\hline $0.65+$ & 100 & 60 & 15 & 9- & - & 3 & 80 & $48+$ & الزيار ات المفاجئة المفتش أسلوب \\
\hline
\end{tabular}

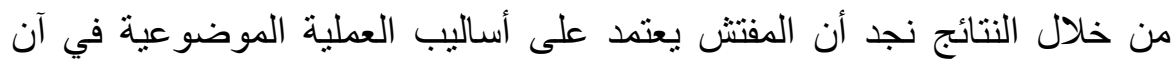

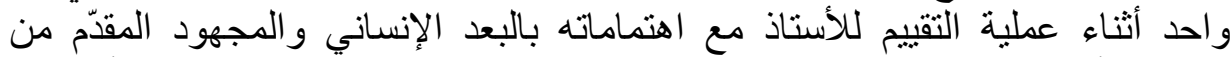

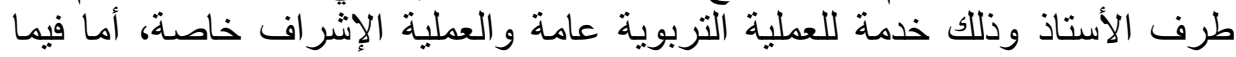

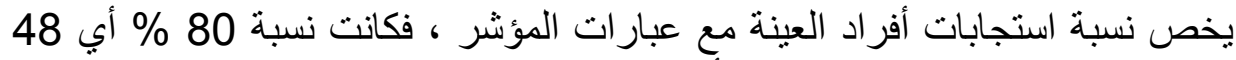

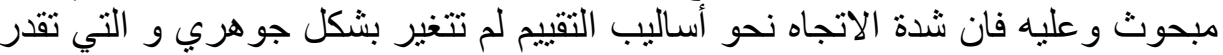

\section{* النتائج العانة للمؤشر الثالث : الجانب التقييمي :}

من خلال دراستنا لاتجاهات أساتذة التعليم الثانوي نجو الجانب التقييمي للمفتش ، تم التمائ

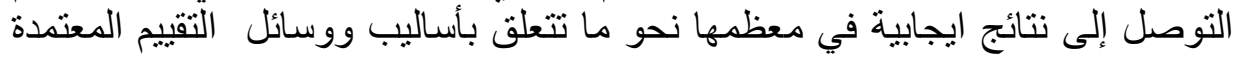

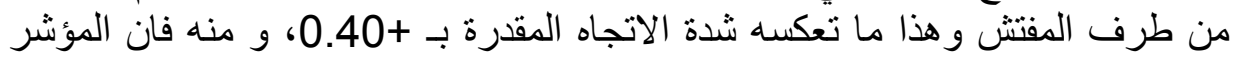
الثالث قد تحقق. و هذا ما يعكس أهمية التقييم و الأسلوب المعتمد في الحكم على أداء الأستاذ فهو

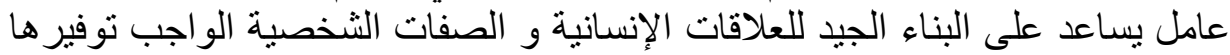
لتهيئة المحيط المدرسي للعملية الإشر افية و العملية التربوية الإنية ككل.

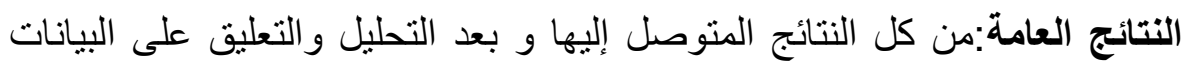

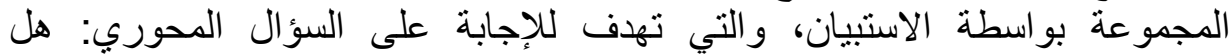

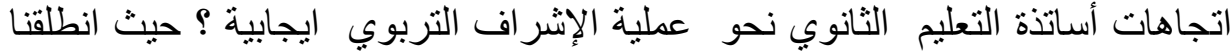
في هذه الدراسة من الفرضية التالية: إن اتجاهات أساتذة التعليم الثانوية نحو التحبة عملية 
الإشر اف التربوي ايجابية، نجد أن فرضية البحث قد تحققت (أثتتت) حيث بلغت شدة

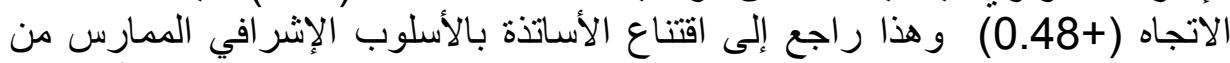

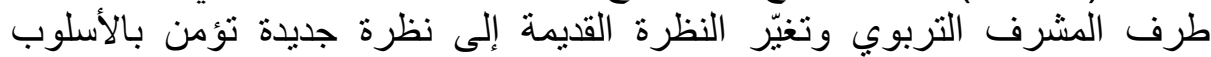

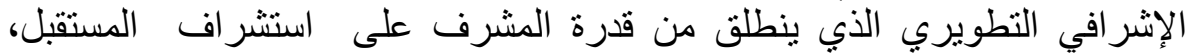

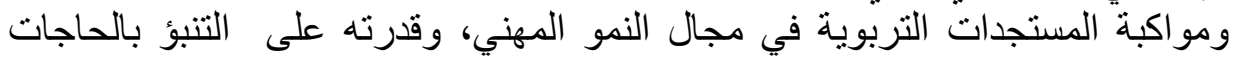

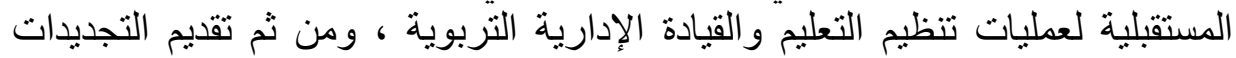

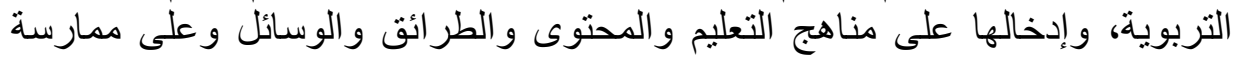

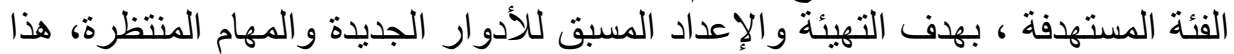

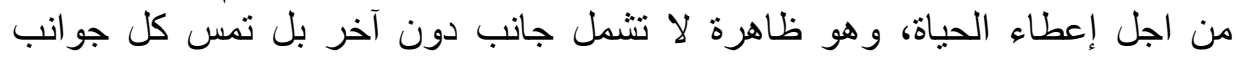

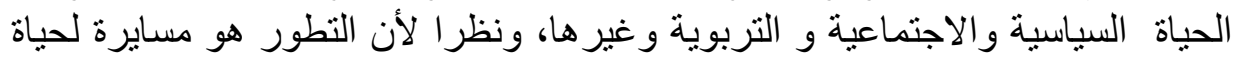

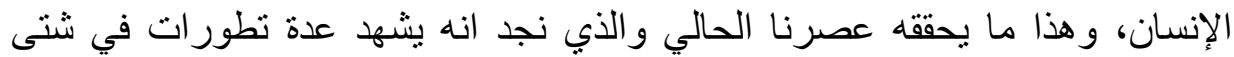

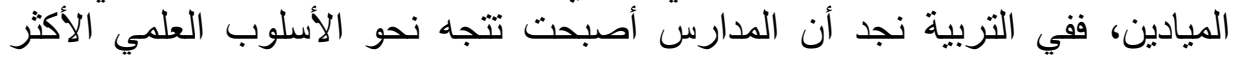

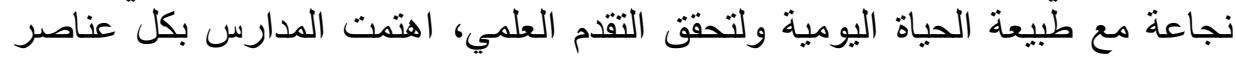

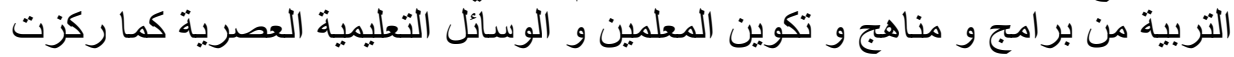

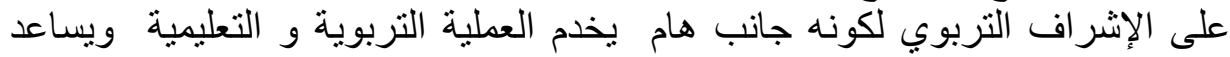

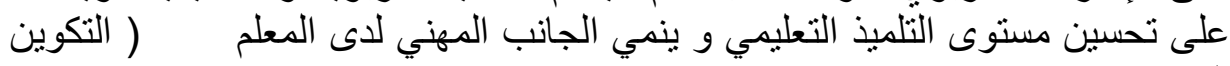
(المستمر).

$$
\text { التوصيات: في ضوء نتائج البحث نصع التوصيات و هي: }
$$

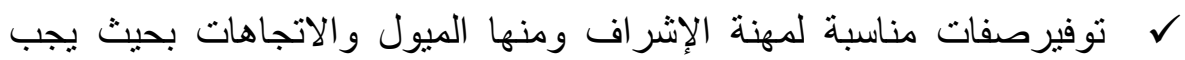
توفير الرغبة والحب اتجاه العمل.

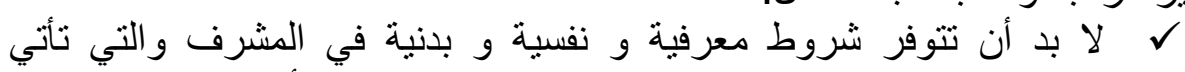

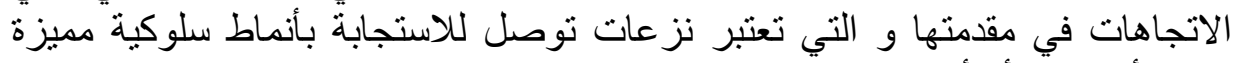
نحو الأشخاص أو أو اضع فكرية معينة.

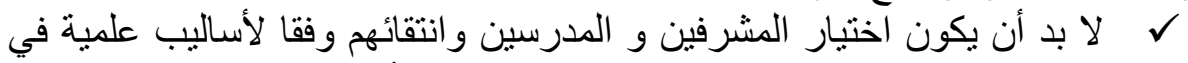

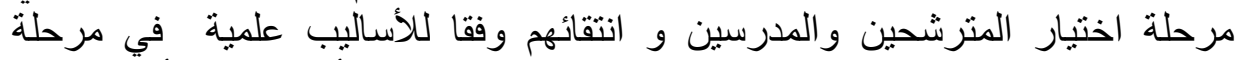

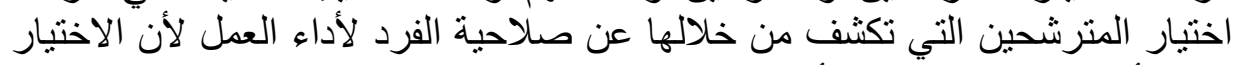
السليم أحد شروط نجاحه في أداء مهنته 


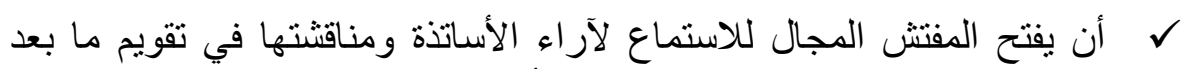

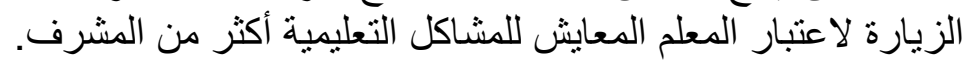

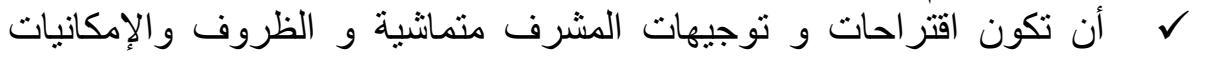
بعيدة عن الإطار النظري.

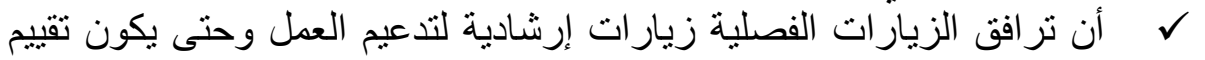

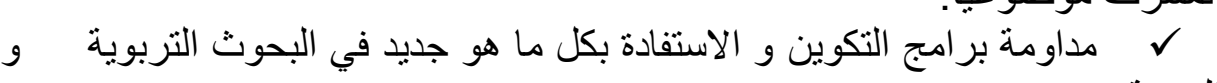

ـ رداح الخطيب وآخرون: الإدارة المدرسية والإشراف التربوي، مطابع الفرزدق التجارية

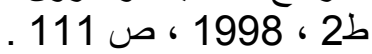
- صلاح الدين علام: القياس و التقويم التربوي والنفسي، أساسياته وتوجهاته وتطبيقاته المعاصرة، دار الفكر العربي، القاهرة، 2000، ص38.

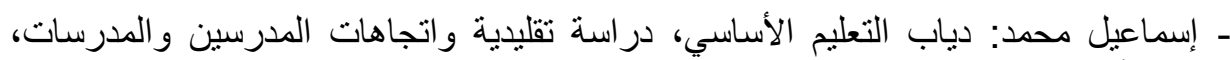

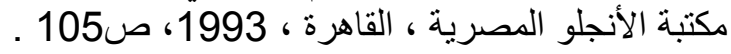

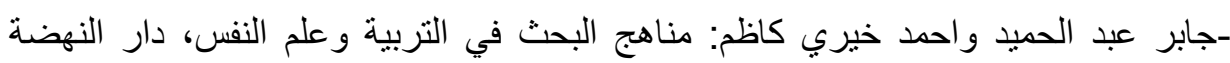

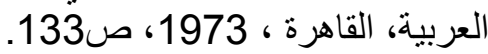
ـ فاخر عاقل: أسس البحث العلمي في العلوم السلوكية، دار العلم للملايين، بيروت، لبنان،ط2،

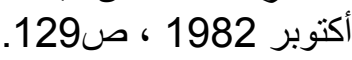

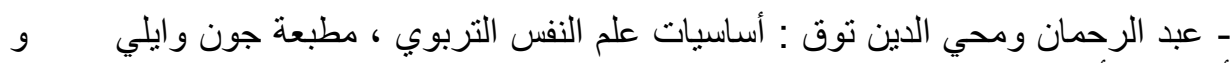
أو لاده، الأردن،1984 الرحمن ، ص110. 
مكي سهام

ـ أنظر النموذج السلوكي ـ المشرف كمحقق لحاجات التلاميذ و المعلمين ، ص6060، نموذج

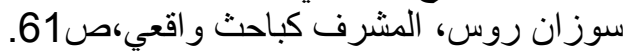

